\title{
A Brief Discussion on the Construction of Artistic Theory Subject from the Perspective of Cultural Research
}

\author{
Yunxiao Wang \\ School of Arts, Hebei University, Baoding 071000, Hebei Province, China
}

\begin{abstract}
Through the past years of development, Chinese native art theories have formed a relatively stable discipline system. In the continuous development process of art, theories for cultural studies have become highly significant. As a matter of fact, since cultural studies has not had a significant impact at present, it still has a strong reference significance for the theoretical development of art theory. Combined with the author's practical experience, it is mainly discussed in this study how to construct the theory of art from the perspective of cultural studies, so as to provide reference for all scholars and readers.
\end{abstract}

Keywords: The Perspective of Cultural Studies; Art Theory; Discipline Construction

\section{Introduction}

It is advisable to make full use of the discipline practice of cultural studies to facilitate the introducing of discipline formation as a conception in the developing of theory of art and discipline construction. In this way, we can combine the humanistic care needed by cultural studies with the theoretical discipline of art, so as to facilitate a better development for the theoretical discipline of art.

\section{The significance of cultural studies to the construction of the theoretical discipline of art}

So far, through theoretical construction and discipline development in China, a relatively mature discipline system of art has been formed. In the current research process, it can be seen that art has begun to take a concrete shape, and in the research perspective of literature and art, some more hot issues have emerged. Through the analysis of these subjects, the theoretical subject of art has become a hot topic at present, and it also ushered in a more desirable period of development. Since the beginning of this year, more attention has been paid in China to the literary theory circle, especially the boundary of the discipline has been less valued. All these are worthy of our in-depth research to strengthen the cultural studies of the theoretical discipline of art. At present, due to the weakening of the boundary of the discipline, it can be seen that the theoretical researchers of literature are paying more attention to it. In the current research process of art, the generalization of the discipline causes the reflection to the art discipline itself. It is necessary to fully combine the literary theory with the current research methods of art, especially to integrate the constructivism of art discipline and the perspective of cultural studies. Through such a method, we can be able to think with more rationality in the construction process of the art discipline. By using the perspective of cultural studies, in-depth analysis can be conducted for the problems that may be encountered in the development of art disciplines, and also to lay a good foundation for the future development of art theory. ${ }^{[1]}$

\section{Discipline construction of art theory from the perspective of cultural studies}

\subsection{To standardize organizational system and fulfill fundamental work}

From the current perspective of the cultural studies, we can establish an integrated development system for the current art discipline, that is, to restrain the development of the art discipline from the inside. With the help of the influence of these systems, the construction of art discipline can be more standardized. By making use of the anti-disciplinary practice of cultural studies, we can strengthen the boundary system of the art discipline. Through the introduction of the discipline system concept, cultural studies have become more specific. As the theory of art itself is a relatively abstract subject, if there is no relevant discipline system, then the theory of art would only stay on the surface, and many illusive ideas may be emerged. Study of culture enable the theoretical construction of art, provide paradigms for research and be critical to one's own institutional construction. Through the in-depth

Copyright (C) 2020 Yunxiao Wang

doi: 10.18282/1-e.v9i3.1579

This is an open-access article distributed under the terms of the Creative Commons Attribution Non-Commercial License

(http://creativecommons.org/licenses/by-nc/4.0/), which permits unrestricted non-commercial use, distribution, and reproduction in any medium, provided the original work is properly cited. 
analysis of these cultural theories and construction systems, internal problems in the construction of art can be identified more clearly, so as to carry out the innovation of literature and art disciplines by starting with the revision of the system, and bring about critical reform from the perspective of cultural studies. Starting from the current art theory and discipline construction, the changes in standardization and institutionalization can be seen, which are having substantial impact. Significant results and positive progress have been achieved at these institutional levels. Art has become a first-level discipline, and the theories of art are also becoming more and more popular, which is an independent subject with the nature of literature and art, while influenced by the current disciplinary culture studies, an integrated discipline system is composed from all these artistic phenomena. Therefore, in the process of institutional construction, fundamental work must be conducted at first. In view of the discipline of art has developed into a first-class discipline, we should maintain a certain sense of anxiety, and take cultural studies as the current direction of reform, and make positive response to the current discipline reform. Traditional disciplines also need to be analyzed on the original parts, extract the essence and remove the dross, and realize the continuous development of art theories through self-improvement. ${ }^{[2]}$

\subsection{Paying attention to one's standpoint to solve a particular problem}

From the researcher's point of view, the standpoint of cultural studies is a very important segment. As far as the current research object is concerned, the standpoints of intellectuals are reflecting the visual and theoretical demands of cultural studies. Therefore, humanistic care in cultural studies must take into account when conducting cultural studies, that is, the objects concerned need to have basic characteristics. In the process of cultural studies, we must fully realize that this is a knowledge activity of high practicalness. We must think about the problems raised and, more importantly, solve the problems encountered. The study of culture is bound to be aimed at solving the problems of a certain culture, so as to solve related problems in a particular historical time or in specific practice, and be able to serve its objects. Because of this, cultural studies have certain local characteristics. Relative to the overall characteristics, cultural studies are required to have feedback on knowledge of locality. That is, the study on the context of locality, which would require to conduct in-depth study of local knowledge and point out the differences in culture. Only in this way, the diversified development of culture can be realized and the legitimacy of minority discourse could be safeguarded. ${ }^{[3]}$ In the course of cultural studies, there are quite a number of diversified cultures. Therefore, based on the perspective of the theory of culture and art, the direction of these studies also needs to be clarified. For example, so far, we have been very comprehensible about art and intangible cultural heritage, but there is still a lot of room for improvement, because intangible cultural heritage is not only an interdisciplinary work, but it may also contain a variety of cultures. In the process of this undertaking, it is necessary to clarify the conception of research on local knowledge, which would be conducive to the construction of our theoretical system of art studies. Some scholars of cultural studies have realized that in cultural studies, it is needed to fundamentally establish certain cultural studies goals and realize the institutionalized development of the discipline. This is not a universal aesthetic work, but a normative one. Cultural studies not only need to inherit the traditional characteristics of culture and art, but also need to find the expression of literature from the past merits. This kind of research itself is the content that should be focused on in the discipline of art theory. The development of any subject needs to be standardized according to certain conceptions and have a certain sense of reflection retained..$^{[2]}$

\section{Conclusion}

In summary, in the construction of the art discipline in China, great progress has been made. Cultural studies have advanced towards a high degree of institutionalization and disciplinization. In the period of increasingly standardized discipline construction, it is necessary to constantly improve the system of cultural studies and improve the literary standardization of art from the perspective of cultural studies. It is also necessary to avoid the pattern that is typical of textbooks for literature, and reserve the liberal identification of ideas and ingenious creation.

\section{References}

1 Zhou Y. Construction and development of the art theory discipline in colleges and universities-A review of "The New Exploration in the Education of the Art Theory Discipline". China Education Journal 2020; (7): 35.

2 Seminar on "The Inheritance of Excellent Traditional Culture and Construction of the Art Theory Discipline" and 2019 Annual Meeting of Zhejiang Art Theory Society. Journal of Aesthetic Education 2019; 10(4): 4.

$3 \mathrm{Jia} \mathrm{T}$. The construction of discipline system in art education-Taking the cognition of art theory discipline and the orientation of curriculum compilation as the study case. Art Scholars 2019; (3): 46-49, 152. 